J. Lake Sci.(湖泊科学), 2020, 32(2): 483-495

DOI 10. 18307/2020. 0217

(c) 2020 by Journal of Lake Sciences

\title{
新疆艾比湖流域枯、丰水期三维荧光光谱特性及其与水质的关系
}

\author{
王 迪 ${ }^{1,2}$, 张 $飞^{1,2,3 * *}$, 张兆永 ${ }^{1,2}$, 张海威 $^{4}$, 朱世 丹 $^{1,2}$, 张贤龙 $^{1,2}$ \\ ( 1 : 新疆大学资源与环境科学学院智慧城市与环境建模自治区普通高校重点实验室,乌鲁木齐 830046) \\ ( 2 : 新疆大学绿洲生态教育部重点实验室,乌鲁木齐 830046) \\ (3: 中亚地理信息开发利用国家测绘地理信息局工程技术研究中心 ,乌鲁木齐 830046) \\ (4: 南京师范大学地理科学学院,南京 210046)
}

\begin{abstract}
摘 要: 以艾比湖流域主要人湖河流为研究对象, 在 5 月 (丰水期) 和 8 月 (枯水期) 分别沿博尔塔拉河 (博河) 和精河进 行采样, 采用平行因子模型 (PARAFAC) 和三维苂光区域积分法对水体三维苂光特性进行研究并对其与水质的关系在 枯、丰水期下的变化进行探讨. 结果表明 (1) 河流 DOM 在枯水期与丰水期都含有 C1 (240、425 nm) UVC 类腐殖质, C2 $(225 、 290 \mathrm{~nm})$ 紫外区内络氨酸类有机物, C3 $(230 / 280 、 330 \mathrm{~nm})$ 蛋白类有机物, C4 $(265 、 260 \mathrm{~nm})$ 腐殖质类共 4 种组分. 通过对水体三维荧光进行区域积分可以看出 DOM 苂光成分的占比在不同时期的变化. 博河在枯水期时 EEM 光谱中的区 域 III 富里酸含量低于丰水期, 枯水期时区域 II 芳香类蛋白质、区域 $I V$ 可溶性微生物代谢物以及区域 $\mathrm{V}$ 类腐殖质酸高于丰 水期; 对于精河来说, 区域 II 芳香类蛋白质和区域 IV 可溶性微生物代谢物在枯水期的含量高于丰水期, 区域 III富里酸和 区域 $\mathrm{V}$ 类腐殖质酸的含量枯水期低于丰水期, 这表明水体腐质化程度较高. (2)本研究选取了一些常规的苂光指数来描述 枯、丰水期水体的苂光指数特性. 经研究发现, 精河的苂光指数、自生源指数和腐殖化指数在不同时期的变化幅度较小, 而博河的变化幅度较大. (3) 将荧光指数与水质参数进行相关性分析并建模, 结果表明枯水期自生源指数 ( $B I X)$ 与化学需 氧量呈显著正相关, 相关系数 $R=0.688$; 丰水期时 $B I X$ 与铵态氮浓度呈显著负相关, 相关系数 $R=-0.493$. 通过对比分析 艾比湖主要人湖河流的三维苂光光谱特性与水质在枯、丰水期时的关系进一步表明水体中 DOM 的特性以及在枯、丰水 期下的差异, 为艾比湖流域的治理改善提供一定的理论支持和参考依据.
\end{abstract}

关键词: 艾比湖流域;水质;三维荧光光谱及平行因子法;荧光区域积分法;荧光指数;博尔塔拉河;精河

\section{Characteristics of three-dimensional fluorescence spectra and its correlation with water quality of surface water during dry and wet seasons in Lake Ebinur Watershed, Xinjiang*}

WANG Di ${ }^{1,2}$, ZHANG Fei ${ }^{1,2,3 * *}$, ZHANG Zhaoyong ${ }^{1,2}$, ZHANG Haiwei ${ }^{4}$, ZHU Shidan ${ }^{1,2}$ \& ZHANG Xianlong $^{1,2}$

(1: Key Laboratory of Smart City and Environmental Modeling of Higher Education Institute, College of Resources and Environment Sciences, Xinjiang University, Urumqi 830046, P.R.China)

(2: Key Laboratory of Oasis Ecology, Xinjiang University, Urumqi 830046, P.R.China)

(3: Engineering Research Center of Central Asia Geoinformation Development and Utilization, National Administration of Surveying, Mapping and Geoinformation, Urumqi 830046, P.R.China)

(4: School of Geographical Sciences, Nanjing Normal University, Nanjing 210046, P.R.China)

Abstract: This study takes the main lakes in Lake Ebinur Watershed as the research object, and samples along the Bortala River and Jing River in May (wet season) and August (dry season). The PARAFAC analysis method and the three-dimensional fluores-

* 2019-05-02 收稿; 2019-08-18 收修改稿.

新疆本地优秀青年培养专项( U1503302)、自治区人民政府公派出国留学成组配套项目 ( L06) 和新疆维吾尔自治 区天山英才项目 (400070010209) 联合资助.

** 通信作者; E-mail:zhangfei3s@163.com. 
cence region integration method is used to study the three-dimensional fluorescence characteristics of water and its seasonal variation with water quality. The results show that: 1) In both dry and wet seasons, river DOM contains C1 (240, $425 \mathrm{~nm}$ ) and C4 (265, $260 \mathrm{~nm})$ kind of humus, C2 $(225,290 \mathrm{~nm})$ uranium-like organic matter compounds. It found that fulvic acid is lower, while the aromatic protein, soluble microbial and humic acid were highest in dry season than wet season in Bortala River. The concentration of the aromatic protein and soluble microbial in dry season was higher than in wet season, and the fulvic acid and humic acid in dry season was lower than in the wet season in Jing River, based on fluorescence regional integral (FRI) analysis and the regional standards related to water quality and fluorescence. This indicates that the degree of decomposition in water is relatively high; 2 ) In this study, some conventional fluorescence indexes were selected to describe the fluorescence index characteristics of water in wet and dry season. It found that the three indexes $(F I, B I X, H I X)$ of the water quality of Jing River and Bortala River in dry and wet seasons showed slight changes, comparing to larger changes in the Bortala River. In general, the change of water quality of Jing River and Bortala River in dry and wet seasons is mainly influenced by microbial activities and human activities; 3 ) In terms of the correlation coefficients of water quality parameters and fluorescence indexes in different seasons, the results showed that the relationship between $B I X$ and COD concentration was best and a significant positive correlation in dry season $(R=0.688, P<0.01)$. Secondly, there is a significant negative correlation between $B I X$ and ammonium nitrogen concentration in wet season $(R=-0.493$, $P<0.05)$. The study provides theoretical support and reference basis for the improvement of the governance of Lake Ebinur Watershed, which further proved that exogenous characteristics and the differences in different periods of DOM sources in the water.

Keywords: Lake Ebinur Watershed; water quality; three-dimensional fluorescence and PARAFAC analysis method; FRI analysis and the regional standards; fluorescence index; Bortala River; Jing River

湖泊及其流域是全球水资源的重要组成部分, 也是人类进行生产生活的重要场所, 对调节河川径流、发 展灌溉农业、提供工业和饮用的水源以及改善区域生态环境等方面起着重大作用. 近些年来艾比湖流域大 力发展经济, 人口剧增,在需水量大幅增长的同时,水体污染也愈发严重. 当下, 对水质进行评价的指标有很 多, 常见的指标有化学需氧量 $(C O D)$ 、溶解氧 $(D O)$ 、五日生化需氧量 $\left(B^{\prime} O D_{5}\right)$ 、总磷 $(T P)$ 、总氮 $(T N)$ 等. 如 张涛等 ${ }^{[1]}$ 、张海威等 ${ }^{[2]}$ 均以一些常规水化学参数对水体进行现状分析及评价. 三维苂光光谱 (3D-EEM) 技术 近年来被广泛用于探索水体 DOM 的来源和特征、地表水环境质量评价和管理等领域,特别是在水土环境、 沉积物、污水与堆肥处理等领域. 通过 EEM 技术可以获得有机物质的有效信息,进而对不同环境中的有机 物成分和动力学因素进行阐述 ${ }^{[3]}$. DOM 作为污染物的重要载体, 影响着污染物的迁移和转化 ${ }^{[4]}$, 主要来源 有来自土壤和调落物等的外源输人, 以及来自微生物活动的内源性输人 ${ }^{[5]}$, 二者共同形成水中 DOM 的化学 结构和组成特征: 同时, 越来越多的有机污染使得水体的 DOM 结构和转化过程更加复杂, 影响了流域的地 表水环境质量.

国外开展对三维荧光的研究较早并取得了迅猛的发展和应用 ${ }^{[6-8]}$, 为大型湖泊和河流的水质监测提供 了潜在应用的可能. 早期国内一些学者利用三维苂光技术对水体 DOM 的性质进行研究, 如: 研究海洋中不 同 DOM 来源的特征 ${ }^{[9]}$ 、近岸水体 DOM 组分变化机制 ${ }^{[10]}$ 、研究表层沉积物溶解性有机物光谱特征 ${ }^{[11]}$ 、暴雨 中 DOM 的光谱特征及来源解析 ${ }^{[12]}$ 、水环境中 DOM 特征及动态、湖泊沉积物等多孔介质中 DOM 组成和分 布 ${ }^{[13]}$ 等方面都能取得很好的效果. 但近些年来利用三维荧光技术对湖泊河流的研究大多只针对某一时期, 而不能探究其在时间序列下的变化. 因此本文开展了基于三维荧光技术的艾比湖流域枯、丰水期下三维荧 光光谱特性及其与水质关系的分析研究.

精河和博尔塔拉河作为艾比湖重要河流维持着该地区乃至整个新疆北部的生态平衡, 1950s - 1970s 艾 比湖流域的主要河流受人口增长和大规模水土开发的影响, 其主要河流出现断流的现象, 现在仅存的博尔 塔拉河与精河的水量大规模减少,水体污染严重,生态环境恶化. 基于此本文以 2018 年 5 月 (汛期) 和 2018 年 8 月 (旱期) 的主要人湖河流——精河和博尔塔拉河为研究区, 采用平行因子分析法 (PARAFAC) ${ }^{[14-15]}$ 与 三维荧光区域积分相结合的方法实现对苂光组分的成分分解 ${ }^{[16]}$, 对枯水期与丰水期下主要人湖河流的 DOM 组分及其相对含量进行定性及定量分析并对其变化情况进行探讨, 其次研究枯、丰水期下的菼光指数 与水质参数之间的关系,为艾比湖流域的治理和生态环境恢复提供理论支持. 


\section{1 研究区概况}

新疆艾比湖湿地国家级自然保护区位于 $\left(44^{\circ} 31^{\prime} 05^{\prime \prime} \sim 45^{\circ} 09^{\prime} 35^{\prime \prime} \mathrm{N}, 82^{\circ} 33^{\prime} 47^{\prime \prime} \sim 83^{\circ} 53^{\prime} 21^{\prime \prime} \mathrm{E}\right.$, 图 1) 并途径 博尔塔拉蒙古自治州、奎屯市、独山子、乌苏市和托里县. 保护区总面积达 $2670.8 \mathrm{~km}^{2}$, 规划保护区核心区面 积 $1054.7 \mathrm{~km}^{2}$, 其中水域面积占 $875.7 \mathrm{~km}^{2}$. 湖区年平均降水量小于 $100 \mathrm{~mm}$, 而山区降水量较大, 是湖区主要 的水源补给区. 湖面呈椭圆状, 平均水深 $2 \sim 3 \mathrm{~m}$, 湖面海拔 $189 \mathrm{~m}^{[17]}$. 博尔塔拉河和精河作为湖水的主要来 源从西面和南面汇人艾比湖. 近些年来由于气候变化和人类活动, 湖水径流量快速减少, 其中水量最大、流 程最长的奎屯河也完全断流 ${ }^{[18]}$. 本研究所选的精河和博尔塔拉河 $\left(44^{\circ} 00^{\prime} \sim 45^{\circ} 23^{\prime} \mathrm{N}, 79^{\circ} 53^{\prime} \sim 83^{\circ} 53^{\prime} \mathrm{E}\right)$ 年径 流量变化较为缓慢, 位于准噶尔盆地的西南缘, 西部、南部、北部三面环山, 东部与准噶尔盆地相连 ${ }^{[19]}$.

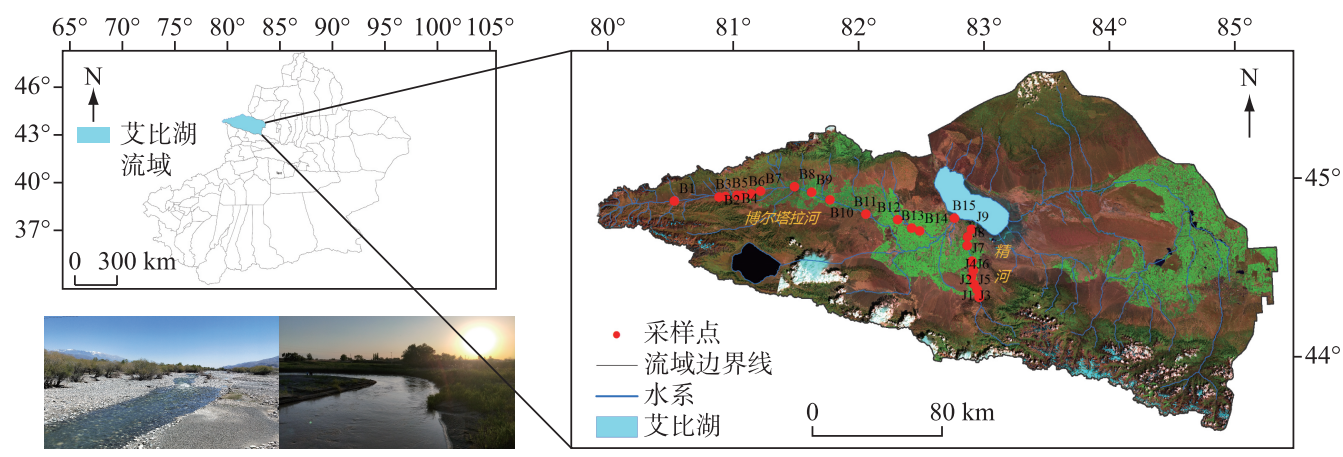

图 1 研究区及采样点示意 (B1 B15 代表博河 15 个采样点, J1 J9 代表精河 9 个采样点)

Fig. 1 Distribution of the research area and sampling sites

\section{2 数据与方法}

\section{1 野外数据的获取与处理}

本文使用的数据采自 2018 年 5 月和 8 月的艾比湖流域,在采集水样的同时, 用 GPS 同步记录采样点的 经纬度坐标. 如图 1 所示, 选取两期各 24 个经纬度重合的采样点作为研究数据进行分析讨论更能反映艾比 湖流域枯、丰水期的水体三维荧光变化.

利用水质检测仪 ( YSI 600) 检测现场采集数据的 $\mathrm{pH}$ 值和溶解氧 ( DO) , 把水样放置在低于 $4^{\circ} \mathrm{C}$ 的冷藏箱 内, 带回实验室测定总磷 $(\mathrm{TP})$ 、化学需氧量 $(\mathrm{COD})$ 、铵态氮 $\left(\mathrm{NH}_{4}^{+}-\mathrm{N}\right)$ 等水质参数 ( 具体测定方法如表 1 所 示), 使用 Whatman GF/F 玻璃纤维过滤器过滤样品, 用 $0.45 \mu \mathrm{m}$ 的滤膜将水样过滤后测定三维苂光光谱 ${ }^{[20]}$.

表 1 水质指标及实验方法

Tab.1 Water indexes and experimental methods

\begin{tabular}{cc}
\hline 参数 & 经验方法 \\
\hline $\mathrm{pH}$ & 利用 $\mathrm{pH}-40 \mathrm{~A}$ 便携式酸度计测定 $\mathrm{pH}$ 值 \\
$\mathrm{DO}$ & 根据碘量法 $(\mathrm{GB} / \mathrm{T} 7489-1987)$, 用可见光光度计 $722 \mathrm{~N}$ 仪器测定水样中 $\mathrm{DO}$ 浓度 \\
$\mathrm{COD}$ & 根据重铬酸钾法 $(\mathrm{GB} 11914-1989)$, 使用标准的 $\mathrm{COD}$ 消解装置 $(\mathrm{K}-100)$ 测定 $\mathrm{COD}$ \\
$\mathrm{TP}$ & 根据锄酸铵分光光度法 $(\mathrm{HJ} 636-2012)$, 用可见光分光光度计 $722 \mathrm{~N}$ 测定 $\mathrm{TP}$ 浓度 \\
$\mathrm{NH}_{4}^{+}-\mathrm{N}$ & 根据纳氏试剂分光光度法, 用可见光分光光度计 $722 \mathrm{~N}$ 测定 $\mathrm{NH}_{4}^{+}-\mathrm{N}$ 浓度 \\
\hline
\end{tabular}

\section{2 研究方法}

2.2.1 荧光光谱分析法 使用 $150 \mathrm{~W}$ 氙灯做为激发光源, 将电压设为 $700 \mathrm{~V}$, 然后使用日本生产的 Hitachi F7000 高灵敏度的苂光光谱分析仪进行分析; 激发波长的扫描范围为 ( Ex) $200 \sim 450 \mathrm{~nm}$, 发射波长 ( Em) 扫描 范围为 $250 \sim 600 \mathrm{~nm}$, 激发和发射波长的增量均设为 $5 \mathrm{~nm}$, 狭缝宽度为 $5 \mathrm{~nm}$, 扫描速度为 $2400 \mathrm{~nm} / \mathrm{min}$. 稀释 
扫描的样品以降低苂光淬灭对样品的影响, 直到其在 $254 \mathrm{~nm}$ 波长处的 UV 吸光度小于 0.1 .

2.2.2 荧光光谱的空白校正 将扫描得到的光谱利用去离子水扣除 $\mathrm{Em}<\mathrm{Ex}+20 \mathrm{~nm}$ 的区域, 可以减少拉曼散 射以及一级瑞利散射对光谱的影响. 通过扣除 $\mathrm{Em}>2 \mathrm{Ex}-20 \mathrm{~nm}$ 的区域消除二级瑞利散射对 EEM 的影响.

2.2.3 平行因子分析法 (PARAFAC) PARAFAC 法是通过使用交替最小二乘原理将由多 EEM 数据组成的 三维阵列 X 分解成三个负载矩阵的方法, 以此来完成三维苂光光谱的解析, 将完成预处理的数据放人 Matlab2012a 软件中进行 PARAFAC, 并且通过残差分析和裂半分析来检验 PARAFAC 模型的有效性, 最终确定 最佳可溶性有机物 (DOM) 组分的数量 ${ }^{[21]}$. 其中, PARAFAC 模型计算公式如下所示 ${ }^{[22-24]}$ :

$$
x_{i j k}=\sum_{j=1}^{F} a_{i f} b_{i j} c_{k f}+e_{i j k}
$$

式中, $x_{i j k}$ 为第 $i$ 个样点在激发波长 $\mathrm{Ex}$ 为 $k$ 、发射波长 $\mathrm{Em}$ 为 $j$ 处的苂光强度; $a_{i j}$ 为因子得分, 表示第 $f$ 个组分 浓度在第 $i$ 个样品浓度中的占比; $b_{i j}, c_{k f}$ 为载荷, 分别是第 $j$ 个发射光谱和第 $k$ 个激发光谱与第 $f$ 个组分的相 对值; $e_{i j k}$ 是残差元素; $F$ 为模型中所设定的组分因子数量.

2.2.4 三维荧光区域积分法 通过计算指定区域的标准体积 $\left(\Phi_{i, n}\right)$ 和总的标准体积 $\left(\Phi_{\mathrm{T}, n}\right)$ 来反映相应区域 中特定结构苂光物质的含量和相对含量的方法就是三维苂光区域积分法 ${ }^{[25-26]}$ :

$$
\begin{gathered}
\Phi_{i}=\sum_{\mathrm{Ex}} \sum_{\mathrm{Em}} I\left(\lambda_{\mathrm{Ex}} \cdot \lambda_{\mathrm{Em}}\right) \Delta \lambda_{\mathrm{Ex}} \cdot \Delta \lambda_{\mathrm{Em}} \\
\Phi_{\mathrm{T}, n}=\sum_{i=1}^{5} \Phi_{i, n} \\
\Phi_{i, n}=M F_{i} \cdot \Phi_{i} \\
P_{i, n}=\frac{\Phi_{i, n}}{\Phi_{\mathrm{T}, n}} \times 100 \%
\end{gathered}
$$

式中, $\Delta \lambda_{\mathrm{Ex}}$ 为激发波长间隔; $\Delta \lambda_{\mathrm{Em}}$ 为发射波长间隔; $I\left(\lambda_{\mathrm{Ex}}, \lambda_{\mathrm{Em}}\right)$ 指对应于激发与发射波长的荧光强度; $P_{i, n}$ 为 苂光物质的相对含量; $M F_{i}$ 是倍乘系数, 区域 I 为 20.4, 区域 II 为 16.4 , 区域 III 为 4.81 , 区域 IV 为 8.76 , 区域 $\mathrm{V}$ 为 1.76 .

2.2.5 荧光指数法 苂光指数 $(F I)$ 是指当激发波长为 $370 \mathrm{~nm}$ 并且发射波长分别为 470 和 $520 \mathrm{~nm}$ 时的苂光 强度的比率, 当 $F I<1.4$ 时 DOM 是陆地或土壤源输人, $F I$ 在 $1.4 \sim 1.9$ 之间表明水体 DOM 是陆源和自生源贡 献相结合, $F I>1.9$ 表明微生物活动强烈, 菼光指数可以区分 DOM 的来源 ${ }^{[27]}$.

自生源指数 $(B I X)$ 是指在激发波长为 $245 \mathrm{~nm}$ 时, 发射波长分别为 380 和 $430 \mathrm{~nm}$ 的苂光强度比率. $B I X>$ 1 表明自生来源主要受生物或细菌的影响, $B I X$ 在 $0.6 \sim 0.7$ 之间表明陆源输人或人类活动对自生源指数的 影响较大, 是反映 DOM 中自生贡献比例的指标 ${ }^{[28]}$.

腐殖化指数 $(H I X)$ 是在 $245 \mathrm{~nm}$ 的激发波长下、435 480 nm 和 $300 \sim 345 \mathrm{~nm}$ 发射波长范围内的平均苂光 强度的比率. 当 $H I X<4$ 时, 表明水体的 DOM 腐殖化程度不强, $H I X$ 在 $10 \sim 16$ 时, 则表明 DOM 具有显著的腐 殖质特征 ${ }^{[27]}$.

\section{3 数据的分析与处理}

本文使用的苂光数据是基于三线性分解理论处理的, 然后对 DOM 的三维苂光光谱进行解谱. 将完成预 处理的数据置于 Matlab2012a 软件中用 DOMFluor 工具箱进行平行因子模型分析, 使用残差分析来测试 PARAFAC 模型的有效性, 并确定最优的 DOM 组分数目 ${ }^{[21]}$. 将所得到的光谱进行扣除去离子水矫正以确保 苂光光谱特性的可比性. 该方法主要包括以下几个关键步骤: 1) 数据的采集与预处理: 包括苂光数据的测 定, 光谱、内滤波、样品浓度的稀释以及散射校正; 2) 异常值的分析处理: 确定和移除所出现的异常值 (在计 算样品的杜杆率时可找到异常值), 通过反复迭代来确定组分数目;3) 模型的确认: 结合实际情况, 反复验证 所得组分的合理性; 4) 模型结果的解译: 通过荧光特性的变化和样品之间组分的比例进行定性和定量的分 析 ${ }^{[21]}$. 同时利用 Matlab2012a 软件对三维荧光光谱进行荧光积分处理以计算整体区域的标准体积的比率.

本文在 ArcGIS 10.2 软件中绘制研究区图以及采样点分布图. 运用 Origin 9.1 软件进行数据分析, 将数 据放人 SPSS 20 软件中进行均值、标准差、方差分析、以及相关性分析, $P<0.05$ 为达到显著检测水平, $P<0.01$ 为极显著水平. 


\section{3 结果与分析}

\section{1 精河与博尔塔拉河水体的苂光组分在枯、丰水期下的特征研究}

采用平行因子分析法对精河与博尔塔拉河不同时期的三维苂光光谱进行分析,结果显示在枯水期和丰 水期下河流的 DOM 组分存在细微差异 (图 2), 从图中可以看出, 河流在枯水期与丰水期的 4 种苂光组分为 C1 $(240,425 \mathrm{~nm})$ UVC 类腐殖质 ${ }^{[29-30]} 、$ C2 $2(225,290 \mathrm{~nm})$ 紫外区内络氨酸类有机物 ${ }^{[31]} 、$ C3 $(230 / 280,330 \mathrm{~nm})$ 类蛋白类有机物 ${ }^{[32-33]}$ 和 $\mathrm{C} 4(265,260 \mathrm{~nm})$ 类腐殖质 ${ }^{[31]}$. 两期数据所解谱出的 4 种组分从总体上看较为相似.

为了更深层次探究 DOM 在枯、丰水期的荧光特性, 本文采用三维荧光区域积分法定量分析 DOM 荧光 组分特征, 使用激发和发射波长将三维苂光光谱分为五个区域 ${ }^{[26,34]}$ : 区域 I ( $\mathrm{Ex} / \mathrm{Em}=220 \sim 250 \mathrm{~nm} / 280 \sim 330$ $\mathrm{nm})$ 为络氨酸类蛋白质; 区域 II $(\mathrm{Ex} / \mathrm{Em}=220 \sim 250 / 330 \sim 380 \mathrm{~nm})$ 为芳香类蛋白质; 区域 III $(\mathrm{Ex} / \mathrm{Em}=220 \sim$ $250 \mathrm{~nm} / 380 \sim 550 \mathrm{~nm}$ ) 为富里酸; 区域 $I V(E x / E m=250 \sim 280 \mathrm{~nm} / 280 \sim 380 \mathrm{~nm}$ ) 为可溶性微生物代谢物; 区域 $\mathrm{V}(\mathrm{Ex} / \mathrm{Em}=220 \sim 250 \mathrm{~nm} / 380 \sim 550 \mathrm{~nm})$ 为类腐殖质酸. 通过计算两期数据特定区域的光谱积分与整体区域 的标准体积的比率, 反映相应区域中苂光物质的含量和相对含量 (图 3).

本文在博河和精河各选取 3 个点进行研究, 可以知道博河在枯水期时区域 I 络氨酸类蛋白质的占比介 于 $17.607 \% \sim 32.797 \%$ 之间, 区域 II 芳香类蛋白质的占比介于 $24.155 \% \sim 28.089 \%$ 之间, 区域 III 富里酸的占比 介于 $3.913 \% \sim 12.403 \%$ 之间，区域IV可溶性微生物代谢物的占比介于 $22.215 \% \sim 31.260 \%$ 之间，区域 V 类腐 殖质酸的占比介于 $8.674 \% \sim 23.064 \%$ 之间; 丰水期时区域 I 络氨酸类蛋白质的占比介于 $16.386 \% \sim 46.148 \%$ 之间，区域 II 芳香类蛋白质的占比介于 $19.665 \% \sim 24.523 \%$ 之间，区域 III 富里酸的占比介于 $6.246 \%$ $21.201 \%$ 之间, 区域 IV 可溶性微生物代谢物的占比介于 $16.744 \% \sim 22.208 \%$ 之间, 区域 V类腐殖质酸的占比介 于 $5.370 \% \sim 17.126 \%$ 之间. 从图 3 中可以看出博河在枯水期时络氨酸类蛋白质和类腐殖质酸的占比有较为 明显的变化. 芳香类蛋白质、可溶性微生物代谢物以及类腐殖质酸在枯水期的占比高于丰水期; 富里酸在丰 水期的占比高于枯水期.

精河在枯水期时区域 I 络氨酸类蛋白质的占比介于 $29.306 \%$ 3 3.254\%之间, 区域 II 芳香类蛋白质的占 比于 $23.406 \%$ 31.157\% 之间, 区域吕富里酸介于的占比 $2.189 \%$ 2 $2.240 \%$ 之间, 区域 IV 可溶性微生物代谢 物的占比介于 $16.608 \% \sim 25.982 \%$ 之间，区域 $\mathrm{V}$ 类腐殖质酸的占比介于 $7.419 \% \sim 7.875 \%$ 之间; 在丰水期时区 域 I 络氨酸类蛋白质的占比介于 $21.189 \%$ 3 $1.588 \%$ 之间, 区域 II 芳香类蛋白质的占比介于 $18.715 \%$ $19.635 \%$ 之间, 区域 III 富里酸的占比介于 $27.433 \% \sim 34.153 \%$ 之间, 区域 IV 可溶性微生物代谢物的占比介于 $11.416 \% \sim 15.125 \%$ 之间, 区域 $\mathrm{V}$ 类腐殖质酸的占比介于 $10.038 \% \sim 11.396 \%$ 之间. 从图 3 中可以看出对于精 河来说, 芳香类蛋白质和可溶性微生物代谢物的占比在枯水期高于丰水期; 富里酸和类腐殖质酸的占比是 丰水期高于枯水期,说明水中腐质化程度较高.

总的来说, 通过利用三维苂光区域积分法将三维苂光光谱主要分为类蛋白物质和类腐殖质物质, 富里 酸的含量受到植被腐烂和微生物活动的影响, 可溶性微生物代谢物在 DOM 组分中的含量从一定程度来说 受到污水排放的影响, 类腐殖酸常出现在河流 DOM 样品中, 来源主要是生物或水生细菌活动所产生的代谢 物 ${ }^{[35]}$. 两条主要人湖河流的芳香类蛋白质以及可溶性微生物代谢物在枯水期的 DOM 组分的占比高于丰水 期,富里酸在丰水期的占比高于枯水期.

\section{2 精河与博尔塔拉河苂光指数在枯、丰水期下的变化}

本文选取 3 个在目前应用广泛的苂光指数来进一步识别 DOM 的组分及性质, 这些指数可以更好地描 述水体在枯水期与丰水期的荧光特性.

精河的三类苂光指数在枯、丰水期下的变化幅度较为平缓,而博河的三类苂光指数变化幅度较大 (图 4). 在枯水期时 2 条河流的 $F I$ 值在 1.9 4.0 之间; 汛期时精河和博尔塔拉河的苂光指数在 1.9 2.8 之间,变 化相对平稳,表明在枯、丰水期 2 条河流中的微生物活动是影响 DOM 组分转化的主要因素.

枯水期时精河与博尔塔拉河的 $B I X$ 值在 1.0 4.7 之间, 大部分样点的 $B I X$ 值在 1 以上且变幅不大; 丰水 期时精河与博尔塔拉河的 $B I X$ 值介于 $0.9 \sim 4.4$ 之间, 其中精河的 $B I X$ 值都在 1 以上. 表明生物或细菌是影响 水体中腐殖质在枯、丰水期下变化的主要原因,DOM 在枯水期时的自生源贡献略大于丰水期. 
(a)
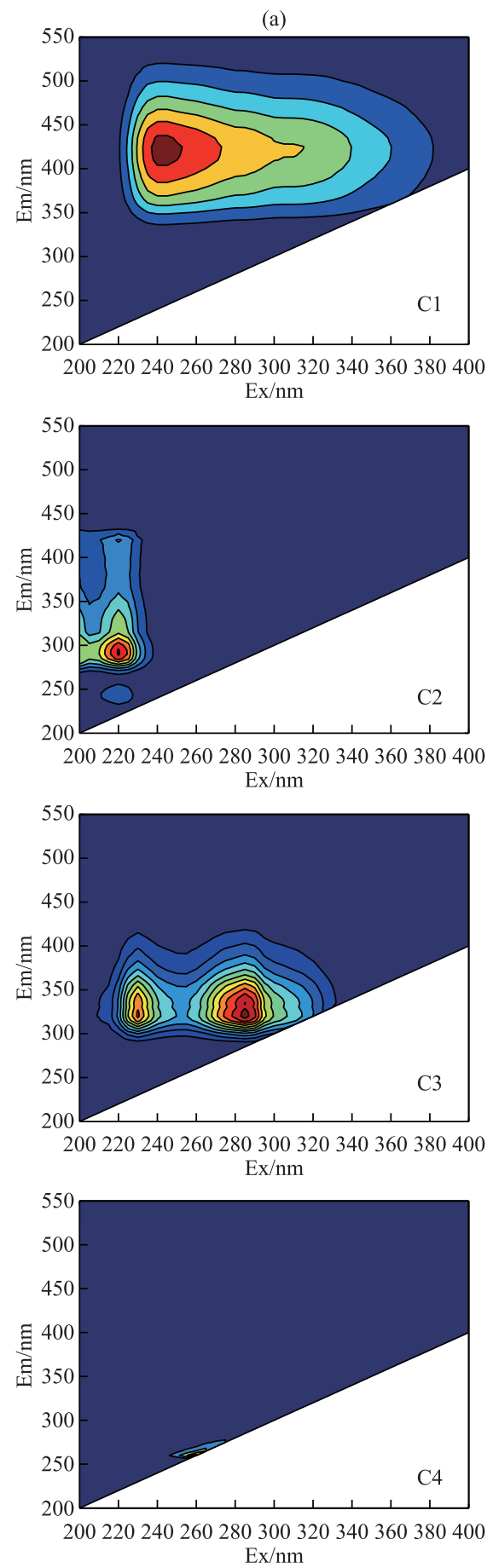

(b)
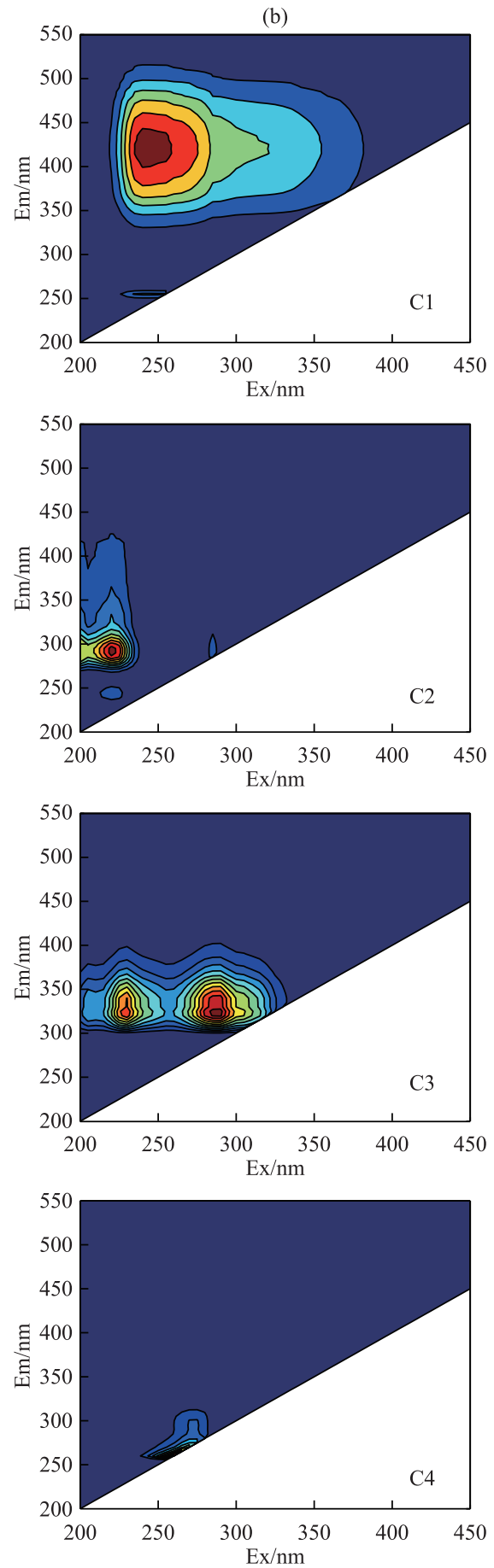

图 2 基于平行因子分析法的枯水期 (a) 和丰水期 (b) 艾比湖流域精河与博尔塔拉河苂光组分

Fig.2 Fluorescence components identified by PARAFAC model in Jing River and Bortala River of Lake Ebinur in dry and wet seasons

博尔塔拉河和精河在枯水期时的 $H I X$ 值介于 $0.3 \sim 2.6$ 之间, 总体上小于 4 , 表明 2 条河流的 DOM 腐殖 化程度均较弱; 汛期时精河和博尔塔拉河水质的 $H I X$ 值在 $0.4 \sim 2.6$ 之间, 两期数据中精河的 $H I X$ 值变幅不 


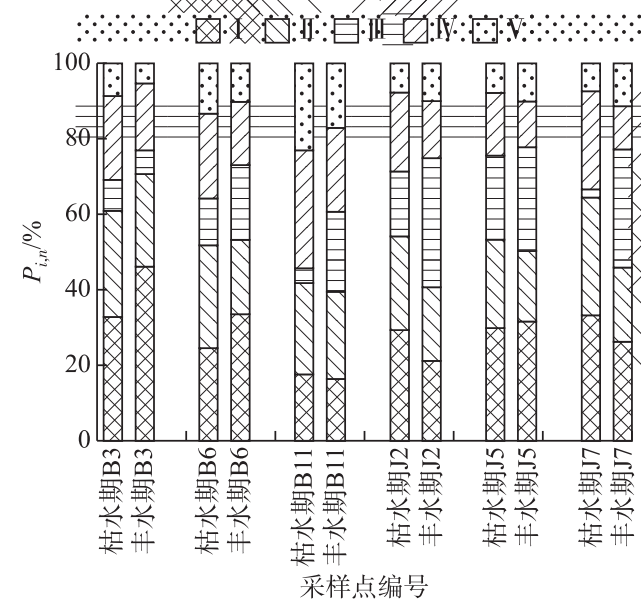

图 3 枯水期和丰水期时精河和博尔塔拉河 DOM 组分的分布

Fig.3 Distribution of the abundance of DOM components in Jing River and Bortala River in dry and wet seasons

大而博尔塔拉河的 $H I X$ 值变幅较大,但 2 条河流的 $H I X$ 值均小于 4 , 表明精河与博尔塔拉河在枯、丰水期 DOM 组分的腐殖化程度均较弱 (图 4). 总体来看, 精河的三类苂光指数在枯、丰水期下的变化较小; 博河在 其下游部分三类苂光指数的变化较大.

DOM 的腐质化程度反映了陆源贡献率的大小, 腐质化程度越高, DOM 的陆源贡献更大 ${ }^{[20]}$. 所以, 精河 与博尔塔拉河水质在枯、丰水期下的变化主要受微生物活动和生物或细菌活动的共同影响.
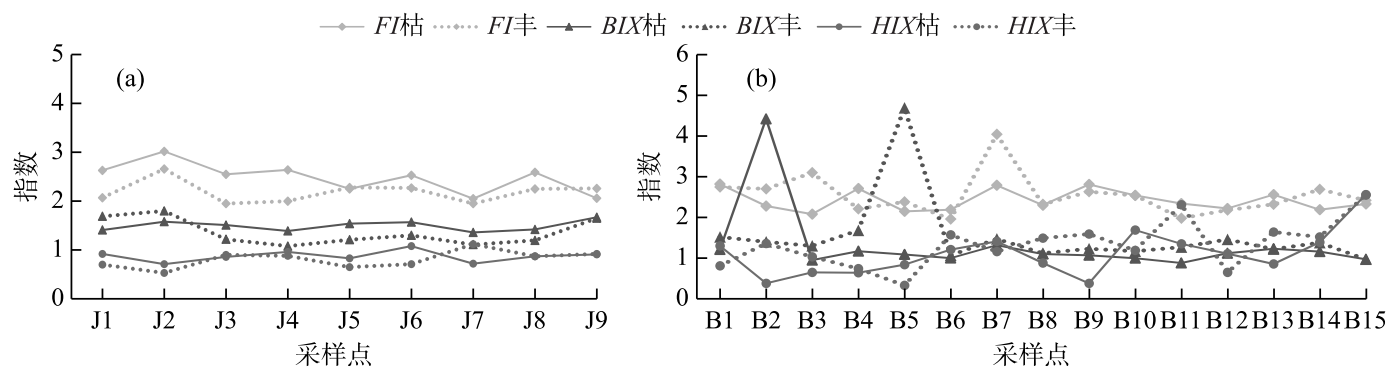

图 4 精河 (a) 和博河 (b) 在枯、丰水期下各采样点苂光指数的变化

Fig.4 Changes of fluorescence indexes in Jing River(a) and Bortala River (b) of each sampling site in dry and wet seasons

\section{3 精河与博尔塔拉河的水质现状}

对精河与博河不同时期下的水体进行分析发现 (图 5), 对于博河来说, 枯水期的 COD 浓度高于丰水期, 在 5 月时博河 COD 浓度的均值与中位数重叠, 说明博河的 COD 浓度在丰水期时变化不大. 而精河在枯、丰 水期下的 COD 浓度变化较小. 两条河流 COD 浓度低于国家《地表水环境质量标准》(GB 3838-2002) V 类 水域功能标准的一倍多, 说明水体中有机污染物浓度较低; DO 浓度可用作间接指标以评估水体受污染程度 及其自我净化的能力. 平均来看, 枯水期时 DO 浓度高于汛期, 精河稍高于博河, 丰水期时两条河流的 DO 浓 度变幅较小,两条河流 DO 浓度平均在 $6 \mathrm{mg} / \mathrm{L}$ 以上,均超出了国家《地表水环境质量标准》( GB $3838-$ $2002) \mathrm{V}$ 类水域功能标准. 其原因可能是由于枯水期时随着气温升高, 河流、湖泊中藻类等水生植物大量生

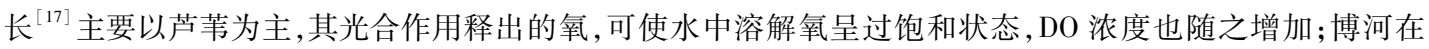
枯、丰水期下的 $\mathrm{NH}_{4}^{+}-\mathrm{N}$ 浓度高于精河, 其中精河在丰水期时 $\mathrm{NH}_{4}^{+}-\mathrm{N}$ 的浓度变幅较小,两条河流 $\mathrm{NH}_{4}^{+}-\mathrm{N}$ 平均 浓度在 $0.3 \mathrm{mg} / \mathrm{L}$ 以上, 均超出了国家《地表水环境质量标准》( GB 3838-2002) V 类水域功能标准的 3 倍; 
两条河流 $\mathrm{pH}$ 的变化范围大致在 $7.1 \sim 7.9$ 之间, 河流呈弱碱性, 枯水期的 $\mathrm{pH}$ 值低于丰水期; TP 浓度是研究 水体富营化的一个重要标志, 从图 5 中可以看出在丰水期时博河 TP 浓度高于精河, 而在枯水期时精河的 TP 浓度稍高于博河, 但总体上, TP 浓度未超出国家《地表水环境质量标准》(GB 3838-2002) 对 V 类水域功能 的标准. 从艾比湖流域附近的城镇居民主要以农业、畜牧业为主的生活方式可以看出, 导致 TP 浓度较高的 原因可能是由于博河附近的施肥面积较大、化肥农药的不合理使用所造成, 在丰水期到来时, 水体中进人了 大量的氮、磷等营养元素, 超过其自净能力, 导致水体中 TP 浓度较高, 出现水体富营养化现象. 综上所述, $\mathrm{pH}$ 与 DO 两种水质参数在枯、丰水期的变化较为明显.
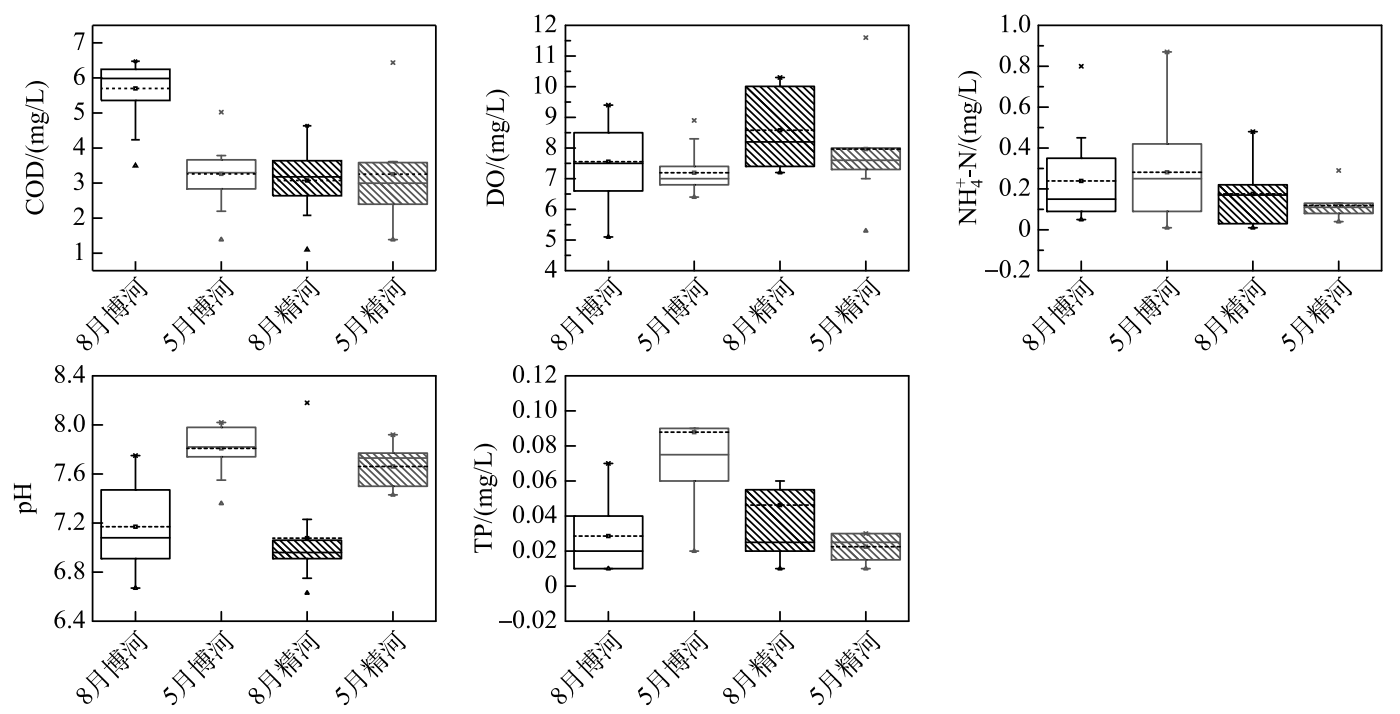

图 5 枯水期和丰水期精河和博尔塔拉河水质参数统计描述

(虚线代表平均值、实线代表中位值)

Fig.5 Statistical description of water quality parameters of Jing River and Bortala River in wet and dry seasons

( The dotted line represents the average and the solid line represents the median)

\section{4 枯、丰水期精河和博尔塔拉河荧光指数与水质参数的关系}

通过观察枯水期与丰水期的两条河流的苂光指数与水质参数相关性发现 (图 6), 枯水期时 $B I X$ 与 COD 浓度和 $\mathrm{NH}_{4}^{+}-\mathrm{N}$ 浓度相关性较强, $B I X$ 与 $\mathrm{COD}$ 的 $R$ 为 0.738 , 呈显著正相关 $(P<0.01)$; 与 $\mathrm{NH}_{4}^{+}-\mathrm{N}$ 浓度的 $R$ 为 -0.722 , 呈显著负相关 $(P<0.05)$; HIX 与 $\mathrm{COD}$ 和 $\mathrm{NH}_{4}^{+}-\mathrm{N}$ 浓度的相关性显著, HIX 与 $\mathrm{COD}$ 浓度的 $R$ 为 0.783 , 呈显著正相关 $(P<0.01) ; \mathrm{HIX}$ 与 $\mathrm{NH}_{4}^{+}-\mathrm{N}$ 浓度的 $R$ 为 0.766 , 呈显著正相关 $(P<0.05) ; B I X$ 与水质参数 $(\mathrm{pH}$ 、 $\mathrm{COD} 、 \mathrm{NH}_{4}^{+}-\mathrm{N}$ ) 之间在丰水期时呈负相关, 与水质参数 ( TP、DO) 之间呈正相关, 与 $\mathrm{COD}$ 浓度和 $\mathrm{NH}_{4}^{+}-\mathrm{N}$ 浓度相 关性显著, 说明生物与细菌活动对枯水期期时河流的 COD 浓度和 $\mathrm{NH}_{4}^{+}-\mathrm{N}$ 浓度有影响; $H I X$ 与水质参数 ( $\mathrm{pH}$ 、 $\left.\mathrm{COD} 、 \mathrm{NH}_{4}^{+}-\mathrm{N}\right)$ 之间均呈正相关, 仅与 $\mathrm{COD}$ 浓度和 $\mathrm{NH}_{4}^{+}-\mathrm{N}$ 浓度相关性显著, $H I X$ 的大小反映 $\mathrm{DOM}$ 组分腐质化 程度, 说明河流中的 $\mathrm{COD}$ 浓度和 $\mathrm{NH}_{4}^{+}-\mathrm{N}$ 浓度与有机质腐殖质的强弱有关 (图 6).

针对图 6 中所表明的枯、丰水期苂光指数与水质参数之间的相关性, 选取相关性较强的苂光指数与水 质参数进行线性函数拟合. 从图 7 中可以看出在枯水期时 $H I X$ 和 $B I X$ 均与 $\mathrm{COD}$ 的关系较好, 且均呈显著正 相关, 相关系数分别为 $R=0.466(P<0.01) / R=0.688(P<0.05)$; 其次为 $B I X$ 和 $H I X$, 与 $\mathrm{NH}_{4}^{+}-\mathrm{N}$ 浓度的关系较 好, 均呈显著正相关, 相关系数分别为 $R=0.418(P<0.01) / R=0.439(P<0.01)$; 在丰水期时 (图 8$) B I X$ 与 $\mathrm{NH}_{4}^{+}-\mathrm{N}$ 浓度的关系最好, 且呈显著负相关, 相关系数为 $R=-0.493(P<0.05)$, 其次为 $F I$ 与 $\mathrm{TP}$ 浓度, 呈显著负 相关, 通过拟合 $R$ 较低. 

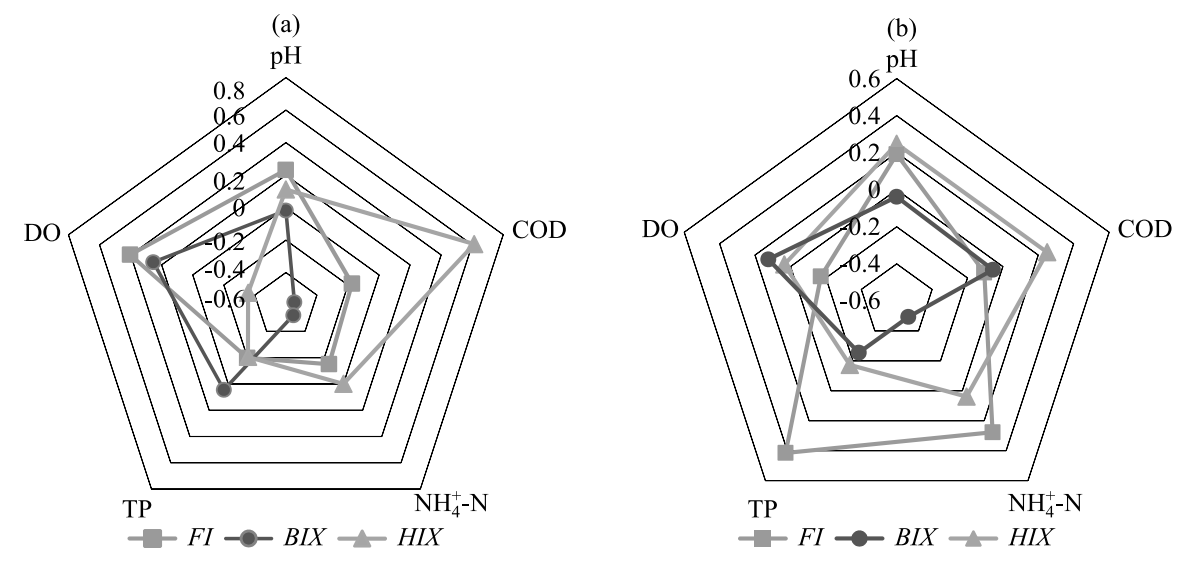

图 6 枯水期 (a) 和丰水期 (b) 的水质参数与菼光指数的相关性

Fig.6 Correlation between water quality parameters and fluorescence indexes in $\operatorname{dry}(a)$ and wet(b) seasons
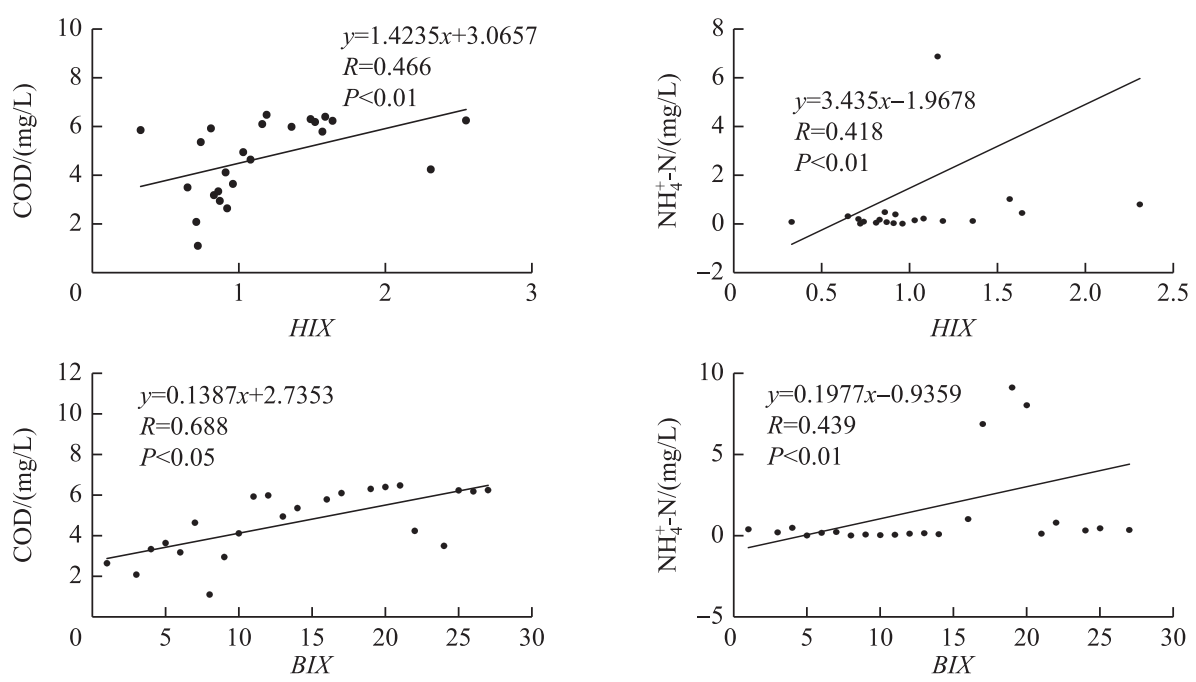

图 7 枯水期水质参数与菼光指数的关系

Fig.7 Relationship between water quality parameters and fluorescence indexes in dry season
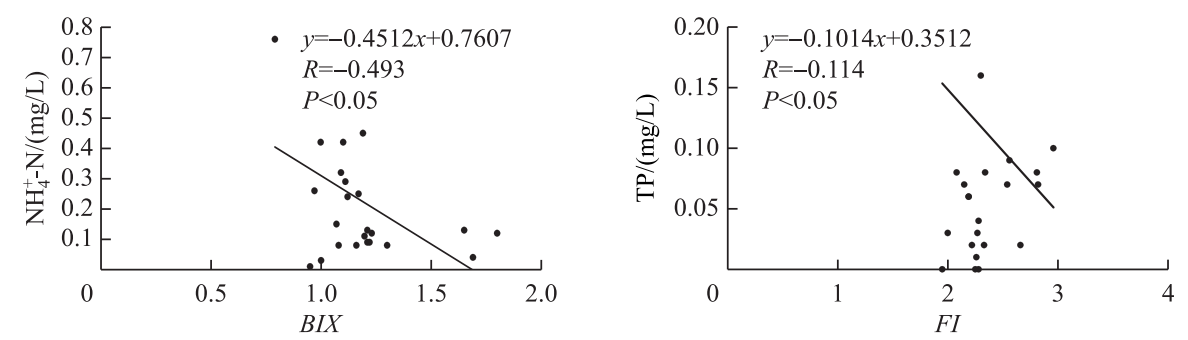

图 8 丰水期水质参数与苂光指数的关系

Fig.8 Relationship between water quality parameters and fluorescence indexes in wet season 

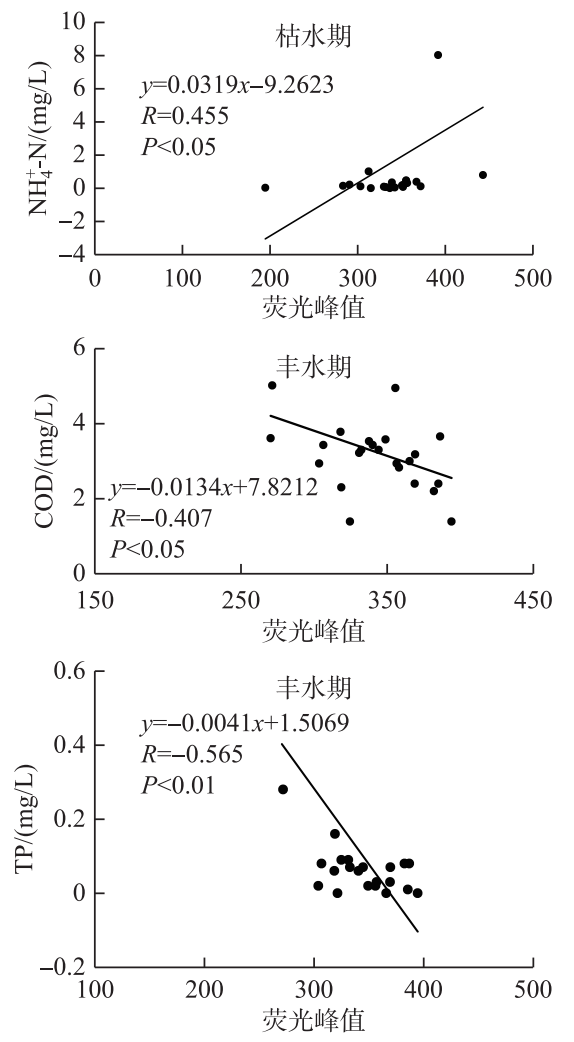

图 9 苂光峰值与水质指标的关系

Fig.9 Relationship between water quality index and fluorescence peak

\section{4 讨论}

1) 通过图 7、图 8 可以知道苂光指数与水质参数的关系之 间存在一定的不确定性, 为了更全面地探究苂光光谱特性与水 质之间的关系, 现将水体的二维苂光峰值与水质参数结合 ${ }^{[36]}$ 进行如下的讨论 (图9): 选取苂光峰最大峰值进行研究, 将苂 光峰值与水质参数 $\mathrm{pH} 、 \mathrm{COD} 、 \mathrm{DO} 、 \mathrm{NH}_{4}^{+}-\mathrm{N} 、 \mathrm{TP}$ 进行相关性分析 可以发现, 在枯水期时, 荧光峰值与水质参数 $\mathrm{NH}_{4}^{+}-\mathrm{N}$ 浓度的相 关性较强; 在丰水期时, 荧光峰值与 COD 和 TP 浓度的相关性 较强. 将相关性较强的苂光峰值与水质参数进行线性拟合 (图 9) 可以看出, 苂光峰值与水质参数 $\mathrm{NH}_{4}^{+}-\mathrm{N}$ 浓度在枯水期时呈 现显著正相关, 相关系数为 $R=0.455, P<0.05$; 荧光峰值与 $\mathrm{COD}$ 和 TP 浓度在丰水期时均呈显著负相关, 相关系数分别为 $R=-0.407, P<0.05 / R=-0.565, P<0.01$. 由此可以看出, 苂光峰 值与水质参数之间确实存在一定的关系, 并且与荧光指数和水 质参数之间有一定联系. 其次, $\mathrm{NH}_{4}^{+} \mathrm{-N} 、 \mathrm{COD}$ 和 TP 是影响精河 与博尔塔拉河水体荧光指数的主导因素, 但对于是什么影响苂 光峰值与水质参数之间的关系还待在后续的研究中继续深人 探讨.

2) 降雨和高山融雪是艾比湖重要的产流方式, 不同补给 的河流在枯水期和丰水期的水体 DOM 来源存在一定的差异, 在其苂光特性上会有所体现, 从图 2 中可以看出精河和博尔塔 拉河在枯水期和丰水期下的苂光组分较为相似, 但还是存在微 小的差异,其原因可能是由于河流补给的来源不同会对水体苂 光光谱产生影响. 除此之外, 2 条河流附近的土地利用/覆被类 型的差异可能也会导致水体苂光光谱发生变化,艾比湖流域附 近的土地利用/覆被类型主要有水域、湿地、盐渍地、林草地和

荒漠等利用类型, 其中盐渍地可分为轻度、中度和重度三类 ${ }^{[37-38]}$, 水体苂光特性的变化是否受河流流经区域 的 LUCC (土地利用/土地覆被变化) 影响以及受哪种土地覆被类型的影响较大是后期研究中需重点探讨的 内容. 从前人的研究中可以得知, 由于人为的破坏, 艾比湖流域水体面积明显减少, 地下水位下降使得荒漠 化进程加剧, 地表水盐分含量增加, 水体苂光组分及苂光指数与地表水盐分均存在一定相关性, 利用三维苂 光光谱技术可以对水体含盐量进行诊断 ${ }^{[39]}$, 在枯、丰水期下水体三维苂光特性存在的差异是否与不同时期 地表水盐分的变化有关是后期需深人探讨的内容.

3) 本文基于前人的研究来进行时间序列上的动态研究, 通过研究三维苂光光谱特性在枯、丰水期下的 变化以及其与水质的关系可以看出精河与博尔塔拉河在枯、丰水期时苂光光谱特性有所不同, 它们与水质 之间存在一定的关系. 但因为本文所探讨的时间周期较短, 重点探讨的是水体三维荧光光谱所具有的特性 及其与水质的有怎样的关系, 对于二者之间的联系有何变化规律会在随后的研究中进一步探讨.

\section{5 结论}

1) 采用平行因子分析法对精河与博尔塔拉河在枯、丰水期的三维苂光光谱进行分析发现两期数据都有 4 组类似的苂光组分, 通过分析博尔塔拉河与精河 5 种 DOM 苂光组分区域在不同时期占比的变化, 可以发 现博河与精河的芳香类蛋白质以及可溶性微生物代谢物在枯水期的浓度高于丰水期, 富里酸在枯水期的浓 度低于丰水期.

2) 通过比较枯水期与丰水期下的主要人湖河流的 3 种苂光指数可以发现, 精河的 3 种苂光指数在枯、 
丰水期下的变化幅度都较小, $F I$ 值都在 1.9 以上, $B I X$ 值大多都在 1 以上, $H I X$ 值整体上小于 4 ; 博尔塔拉河 的 3 种荧光指数在枯、丰水期下的变幅较大, 其中 $F I$ 值都在 1.9 以上, $B I X$ 值大多都在 0.9 以上, $H I X$ 值在 $0.3 \sim 2.6$ 之间, 整体上小于 4. 由此可以看出, 精河与博尔塔拉河水质在枯水期与丰水期的苂光指数变化主要 受到微生物活动及生物或细菌的共同影响, 人类活动对水体菼光指数的影响较小.

3 ) 对枯水期和丰水期 2 条河流的水质进行研究发现,博河的 COD 在枯水期时高于丰水期,精河的 COD 变化不大; DO 浓度的变化平均来看是河流在枯水期的浓度大体高于汛期,精河 DO 浓度稍高于博河; 精河的 $\mathrm{NH}_{4}^{+}-\mathrm{N}$ 浓度在丰水期变化较小, 平均浓度低于枯水期; 2 条河流 $\mathrm{pH}$ 的变化范围大致在 7.1 7.9 之间, 河流呈 弱碱性,枯水期的 $\mathrm{pH}$ 较低; 丰水期时博河 TP 浓度高于精河,而在枯水期时 2 条河流的 TP 浓度基本持平.

4) 通过计算枯、丰水期下两条河流荧光指数与水质参数的相关性发现,枯水期时 $H I X$ 与 COD 和 $\mathrm{NH}_{4}^{+}-\mathrm{N}$ 浓度相关性均较强, 丰水期时 $F I$ 与 $\mathrm{TP}$ 浓度以及 $B I X$ 与 $\mathrm{NH}_{4}^{+}-\mathrm{N}$ 浓度的相关性较强, 将相关性较强的苂光指 数与水质参数选取出来进行函数拟合可以得到, 在枯水期 $B I X$ 与 $\mathrm{COD}$ 呈显著正相关, 相关系数为 $R=0.688$ $(P<0.05)$; 在丰水期 $B I X$ 与 $\mathrm{NH}_{4}^{+}-\mathrm{N}$ 浓度呈显著负相关, 相关系数为 $R=-0.493(P<0.05)$. 这表明枯水期时生 物或细菌的活动会对 COD 产生较大影响; 丰水期时生物或细菌活动会对 $\mathrm{NH}_{4}^{+}-\mathrm{N}$ 浓度产生较大影响.

\section{6 参考文献}

[ 1 ] Zhang T, Chen QW, Yi QT et al. Spatial and seasonal variations of water quality in the upstream plain river networks of the Taihu Basin. J Lake Sci, 2017, 29(6) : 1300-1311. DOI: 10.18307/2017.0602. [张涛, 陈求稳, 易齐涛等. 太湖 流域上游平原河网区水质空间差异与季节变化特征. 湖泊科学, 2017, 29(6)：1300-1311.]

[ 2 ] Zhang HW, Zhang W, Li Z et al. Spectral diagnosis and spatial distribution of SS, TN and TP in surface water in Ebinur Lake Watershed. Ecology and Environment Sciences, 2017, 26(6): 1042-1050. [张海威, 张飞, 李哲等. 艾比湖流域 地表水水体悬浮物、总氮与总磷光谱诊断及空间分布特征. 生态环境学报, 2017, 26(6) : 1042-1050.]

[ 3 ] Goldman JH, Rounds SA, Needoba JA. Applications of fluorescence spectroscopy for predicting percent wastewater in an urban stream. Environmental Science \& Technology, 2012, 46(8) : 4374-4381.

[ 4 ] Kalbitz K, Solinger S, Park JH et al. Controls on the dynamics of dissolved organic matter in soils: A review. Soil Science, $2000, \mathbf{1 6 5}(4)$ : 277-304.

[ 5 ] Hudson N, Baker A, Reynolds D. Fluorescence analysis of dissolved organic matter in natural, waste and polluted waters-A review. River Research and Applications, 2007, 23(6) : 631-649.

[ 6 ] Cheng Y, Hu X, Du JQ et al. Characteristics of three-dimensional fluorescence on CDOM of the sewage into city segment of a typical northwest inland river. Zhongguo Huanjing Kexue/China Environmental Science, 2018, 38(7) : 2680-2690.

[ 7 ] Zhao N, Zhang X, Yin G et al. On-line analysis of algae in water by discrete three-dimensional fluorescence spectroscopy. Optics Express, 2018, 26(6): A251.

[ 8 ] Stedmon CA. Tracing dissolved organic matter in aquatic environments using a new approach to fluorescence spectroscopy. Mar Chem, 2003, 82.

[ 9 ] Murphy KR, Stedmon CA, Waite TD et al. Distinguishing between terrestrial and autochthonous organic matter sources in marine environments using fluorescence spectroscopy. Marine Chemistry, 2008, 108(1/2): 40-58.

[10] Yamashita Y, Jaffé R, Maie N et al. Assessing the dynamics of dissolved organic matter (DOM) in coastal environments by excitation emission matrix fluorescence and parallel factor analysis (EEM-PARAFAC). Limnology and Oceanography, $2008, \mathbf{5 3}(5):$ 1900-1908.

[11] Wang XJ, Huang TL, Li N et al. Spectral characteristics of dissolved organic matter in the surface sediments from a canyon-shaped, stratified, water-source reservoir. J Lake Sci, 2018, 30(6) : 1625-1635. DOI: 10.18307/2018.0614. [王晓 江, 黄廷林, 李楠等. 峡谷分层型水源水库表层沉积物溶解性有机物光谱特征. 湖泊科学, 2018, 30(6): 1625-1635.]

[12] Zhou SL, Zhang YR, Huang TL et al. Spectral characteristics and sources of rainstorms dissolved organic matter in Zhoucun Reservoir during flood season. J Lake Sci, 2019, 31(2) : 493-506. DOI: 10.18307/2019.0218. [周石否, 张艺苒, 黄廷林等. 周村水库汛期暴雨中溶解有机物 (DOM) 的光谱特征及来源解析. 湖泊科学, 2019, 31(2) : 493-506.]

[13] Chen JY, Wang SH, Jiang X et al. Fluorescence spectral characteristics of fluorescent dissolved organic matter (FDOM) 
in the surface sediments from Lihu Lake. Environmental Science, 2017, 38(1): 70-77. [ 陈俊伊, 王书航, 姜霞等. 蝴 表层沉积物荧光溶解性有机质 (FDOM) 苂光光谱特征. 环境科学, 2017, 38(1) : 70-77.]

[14] Hudson N, Baker A, Ward D et al. Can fluorescence spectrometry be used as a surrogate for the Biochemical Oxygen Demand (BOD) test in water quality assessment? An example from South West England. Science of the Total Environment, 2008, 391 (1) : 149-158.

[15] Posburn CL, Handsel LT, Mikan MP et al. Fluorescence tracking of dissolved and particulate organic matter quality in a river-dominated estuary. Environmental Science \& Technology, 2012, 46(16) : 8628-8636.

[16] Yu H, Song Y, Du E et al. Comparison of PARAFAC components of fluorescent dissolved and particular organic matter from two urbanized rivers. Environmental Science \& Pollution Research International, 2016, 23(11) : 1-12.

[17] Mi Y, Chang SL, Shi QD et al. Study on the effect of agricultural non-point source pollution to water environment of the Ebinur Lake Basin during high flow period. Arid Zone Research, 2010, 27(2): 278-283. [弥艳, 常顺利, 师庆东等. 农 业面源污染对丰水期艾比湖流域水环境的影响. 干旱区研究, 2010，27(2)：278-283.]

[18] Zhu SD, Zhang F, Zhang HW et al. Seasonal variation of the isotope and hydrochemical characteristics of the main lake rivers in Lake Ebinur, Xinjiang. J Lake Sci, 2018, 30(6) : 1707-1721. DOI: 10.18307/2018.0622. [ 朱世丹, 张飞, 张 海威等. 新疆艾比湖主要人湖河流同位素及水化学特征的季节变化. 湖泊科学, 2018, 30(6) : 1707-1721.]

[19] Zhang HW, Zhang F, Li Z et al. Characteristics of three dimensional fluorescence spectra and its correlation with water quality in Jinghe and Bortala River from Lake Ebinur's major inflow tributaries, Xinjiang. J Lake Sci, 2017, 29(5) : 11121120. DOI: $10.18307 / 2017.0509$. [张海威, 张飞, 李哲等. 新疆艾比湖主要人湖河流精河与博尔塔拉河三维苂光 光谱特性及其与水质的关系. 湖泊科学, 2017, 29(5): 1112-1120.]

[20] Fan SY, Qin JH, Liu YY et al. Seasonal variations of dom spectral characteristics in the surface water of the upstream Minjiang River. Environmental Science, 2018, 39(10): 4530-4538. [范诗雨, 秦纪洪, 刘堰杨等. 捤江上游水体中 DOM 光谱特征的季节变化. 环境科学, $2018,39(10): 4530-4538$. ]

[21] Stedmon CA, Bro R. Characterizing dissolved organic matter fluorescence with parallel factor analysis: A tutorial. Limnology and Oceanography: Methods, 2008, 6(11) : 572-579.

[22] Zhou Y, Shi K, Zhang Y et al. Fluorescence peak integration ratio IC: IT as a new potential indicator tracing the compositional changes in chromophoric dissolved organic matter. Science of the Total Environment, 2017, 574: 1588-1598.

[23] Baghoth SA, Sharma SK, Amy GL. Tracking natural organic matter (NOM) in a drinking water treatment plant using fluorescence excitation-emission matrices and PARAFAC. Water Research, 2011, 45(2) : 797-809.

[24] Zhu P, Hua ZL, Li HM. Application of parallel factor analysis method of the three-dimensional fluorescence spectra in source apportionment of pollutions in water environment. Spectroscopy and Spectral Analysis, 2012, 32(12) : 3290-3294. [祝鹏, 华祖林, 李惠民. 湖泊水体三维苂光光谱的 PARAFAC 法在污染源解析中的应用. 光谱学与光谱分析, 2012, 32(12) : 3290-3294.]

[25] Huguet A, Vacher L, Stéphane R et al. Properties of fluorescent dissolved organic matter in the Gironde Estuary. Organic Geochemistry, 2009, 40(6): 706-719.

[26] Chen W, Westerhoff P, Leenheer JA et al. Fluorescence excitation-emission matrix regional integration to quantify spectra for dissolved organic matter. Environmental Science \& Technology, 2003, 37(24) : 5701-5710.

[27] Cory RM, Mcknight DM. Fluorescence spectroscopy reveals ubiquitous presence of oxidized and reduced quinones in dissolved organic matter. Environmental Science \& Technology, 2005, 39(21) : 8142-8149.

[28] Wang Z, Wu Z, Tang S. Characterization of dissolved organic matter in a submerged membrane bioreactor by using threedimensional excitation and emission matrix fluorescence spectroscopy. Water Research, 2009, 43(6) : 1533-1540.

[29] Hur J, Cho J. Prediction of BOD, COD, and total nitrogen concentrations in a typical urban river using a fluorescence excitation-emission matrix with PARAFAC and UV Absorption Indices. Sensors, 2012, 12(12) : 972-986.

[30] Cheng QL, Zheng BH, Wang SR et al. Optical signatures of chromophoric dissolved organic matter in water body of Tien Lake. Spectroscopy and Spectral Analysis, 2014, 34(3): 698-703. [程庆霖, 郑丙辉, 王圣瑞等. 滇池水体有色溶解性 有机质 (CDOM) 三维苂光光谱特征. 光谱学与光谱分析, 2014, 34(3): 698-703.]

[31] Feng WY, Wang SR, Zhang S et al. Effect of $\mathrm{pH}$ on the fluorescence characteristics of dissolved organic matter in the sediment and overlying water from Erhai Lake. Environmental Chemistry, 2014, 33(2): 229-235. [冯伟芗, 王圣瑞, 张生 等. $\mathrm{pH}$ 对洱海沉积物-上覆水溶解性有机质苂光特征影响. 环境化学, 2014, 33(2) : 229-235.] 
[32] Ma LN, Zhang H, Tan WB et al. Evolution of dissolved organic matter properties in a constructed wetland of Xiao River, Hebei. Spectroscopy and Spectral Analysis, 2016, 36(1): 206-212. [马丽娜, 张慧, 檀文炳等. 河北洨河人工湿地水 体溶解性有机物性质的演化过程研究. 光谱学与光谱分析, 2016, 36(1) : 206-212.]

[33] Wang QL, Jiang T, Zhao Z et al. Spectral characteristics of Dissolved Organic Matter (DOM) in waters of typical agricultural watershed of Three Gorges Reservoir areas. Environmental Science, 2016, 37(6): 2082-2092. [王齐否, 江韬, 赵 铮等. 三峡库区典型农业小流域水体中溶解性有机质的光谱特征. 环境科学, 2016, 37 (6) : 2082-2092.]

[34] Vodacek A, Hoge FE, Swift RN et al. The use of in situ and airborne fluorescence measurements to determine UV absorption coefficients and DOC concentrations in surface waters. Limnology and Oceanography, 1995, 40(2) : 411-415.

[35] Lin XY, Wang SM, Li Q et al. Water quality and three-dimensional fluorescence of stormwater runoff from lined bioretention field cells. Environmental Science, 2018, 39(10): 4539-4546. [林修咏, 王书敏, 李强等. 防渗型生物滞留中试 系统降雨径流水质与三维荧光特征. 环境科学, 2018, 39(10) : 4539-4546.]

[36] Zhang XL, Zhang F, Zhang HW et al. The preliminary study on the relationship between two dimensional fluorescence peak value of surface water and water quality indexes in Ebinur Lake Basin. Spectroscopy and Spectral Analysis, 2018,38 (2) : 481-487. [张贤龙, 张飞, 张海威等. 艾比湖流域地表水二维苂光峰值与水质指标关系初探. 光谱学与光谱 分析, 2018, 38(2): 481-487.]

[37] Sun Q, Aliya B, Ilyas N. Effect of LUCC change on evolution of landscape pattern in Ebinur Wetland. Soil, 2018, 50 (3) : 583-592. [孙倩, 阿丽亚·拜都热拉, 依力亚斯江 · 努尔麦麦提. 新疆艾比湖湿地 LUCC 对景观格局演变的 影响. 土壤, 2018, 50(3): 583-592.]

[38 ] Jing YQ, Zhang F, Chen LH et al. Investigation on eco-environmental effects of land use/cover-landscape pattern and climate change in Ebinur Lake Wetland Nature Reserve. Acta Scientiae Circumstantiae, 2017, 37(9) : 3590-3601. [井云 清, 张飞, 陈丽华等. 艾比湖湿地土地利用/覆被-景观格局和气候变化的生态环境效应研究. 环境科学学报, 2017, 37(9) : 3590-3601.]

[39] Wang XP, Zhang F, Yang ST et al. Rapid diagnosis of surface water salt content (WSC) in Ebinur Lake Watershed based on 3-D fluorescence technology. Spectroscopy and Spectral Analysis, 2018, 38(5) : 1468-1475. [王小平, 张飞, 杨胜天 等. 基于三维苂光技术的艾比湖流域地表水盐分快速诊断研究. 光谱学与光谱分析, 2018, 38(5): 1468-1475.] 